\title{
Review Article \\ Human Metabolic Enzymes Deficiency: A Genetic Mutation Based Approach
}

\author{
Swati Chaturvedi, ${ }^{1}$ Ashok K. Singh, ${ }^{1}$ Amit K. Keshari, ${ }^{1}$ Siddhartha Maity, ${ }^{2}$ \\ Srimanta Sarkar, ${ }^{3}$ and Sudipta Saha ${ }^{1}$ \\ ${ }^{1}$ Department of Pharmaceutical Sciences, Babasaheb Bhimrao Ambedkar University, Raebareli Road, Vidyavihar, \\ Lucknow 226025, India \\ ${ }^{2}$ Department of Pharmaceutical Technology, Jadavpur University, Kolkata 700032, India \\ ${ }^{3}$ Dr. Reddy's Laboratories Limited, Bachupally, Hyderabad, Telangana 502325, India
}

Correspondence should be addressed to Sudipta Saha; sudiptapharm@gmail.com

Received 1 December 2015; Revised 21 January 2016; Accepted 31 January 2016

Academic Editor: Gary Lopaschuk

\begin{abstract}
Copyright ( $(2016$ Swati Chaturvedi et al. This is an open access article distributed under the Creative Commons Attribution License, which permits unrestricted use, distribution, and reproduction in any medium, provided the original work is properly cited.

One of the extreme challenges in biology is to ameliorate the understanding of the mechanisms which emphasize metabolic enzyme deficiency (MED) and how these pretend to have influence on human health. However, it has been manifested that MED could be either inherited as inborn error of metabolism (IEM) or acquired, which carries a high risk of interrupted biochemical reactions. Enzyme deficiency results in accumulation of toxic compounds that may disrupt normal organ functions and cause failure in producing crucial biological compounds and other intermediates. The MED related disorders cover widespread clinical presentations and can involve almost any organ system. To sum up the causal factors of almost all the MED-associated disorders, we decided to embark on a less traveled but nonetheless relevant direction, by focusing our attention on associated gene family products, regulation of their expression, genetic mutation, and mutation types. In addition, the review also outlines the clinical presentations as well as diagnostic and therapeutic approaches.
\end{abstract}

\section{Introduction}

Understanding of metabolism and energy flow through cells has recently gained considerable interest [1]. Inborn error of metabolism (IEM) is a group of disorders characterized by a single gene defect, which blocks some vital steps in the normal metabolic pathway ensuing in deposition of substrate or insufficiency of the product for normal organ functions [2]. Diagnosis is of foremost choice not only for treatment and prognosis but also for genetic counseling [3]. Enzyme deficiency is thought to be genetically inherited almost always in a recessive fashion, as it is mainly the result of "lossof-function" mutations [4]. This can be inherited either as autosomal recessive (both of the parents do not have disorder but each of them carries faulty gene and delivers it to the child) or as X-linked recessive (only the mother carries the affected gene on the $\mathrm{X}$ chromosome and conveys it to the child) [5].
The inheritance of the majority of metabolic disorders is rare [6] and the age of onset is extremely variable; however, IEMs afflict mostly the paediatric population [2]. Early detection of IEM correlates with significant reduction in associated disabilities and deaths [6]. Genetic mutation is also responsible for enzyme defect that regulates enzyme protein interaction during transportation and binding of cofactors. As a result, there is a modification in cellular chemistry either by diminution of essential component or by accumulation of toxic substances [4].

Treatment approaches for metabolic disorders are based on symptomatic therapy which may include (a) modification of metabolism process through restriction of attachment of precursor with enzymes; [4] (b) provocation and stabilization of residual enzyme activity using cofactors or vitamins; (c) blocking the production of toxic metabolites using detoxifying agents; [7] (d) replacement therapy to supply exogenous functional enzymes; (e) endogenous production of enzymes 


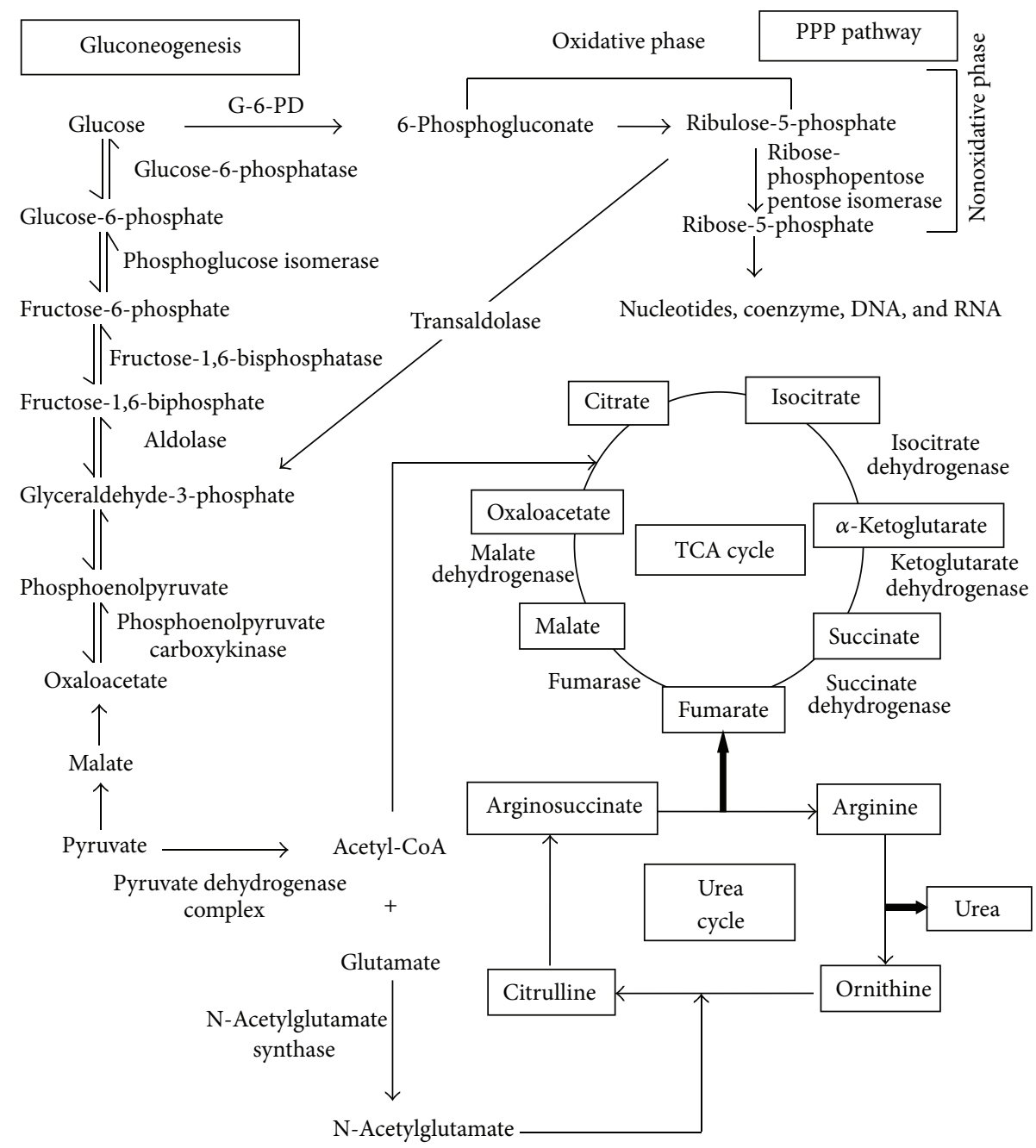

Figure 1: Interlinking between various metabolic pathways (gluconeogenesis, Krebs cycle, urea cycle, and pentose phosphate) and various enzymes responsible for metabolism.

through organ transplantation; (f) gene therapy to replace defective gene [4]; (g) avoidance of catabolism at all stages of treatment. Nonetheless, the nutrition therapy is considered as an integral part for the treatment of IEM. Few parameters are essential for assessment of IEM which include nutrient intake, growth rate, and laboratory values monitoring $[7,8]$.

Hitherto, despite the appearance of quite a few excellent reviews in the field of IEM of the literature, no review has focussed on summarizing the real correlation of human metabolic enzyme deficiency (MED) with inborn error of metabolism (IEM), particularly in the sense of genetic mutation. The aim of this review is, therefore, to provide the most advanced information about the key enzymes critically involved in diverse well-known metabolic pathways like gluconeogenesis, Krebs cycle, urea cycle, and pentose phosphate (PPP) pathway (Figure 1). The emphasis here is given to how genetic mutation or altered gene expression affects MED-associated disorders. Table 1 represents the summarized form of metabolic enzymes deficiency disorders and genetic mutations.

\section{Metabolic Enzymes Deficiency: Cause and Complications}

2.1. Glucose-6-phosphatase (G6Pase) Deficiency. G6Pase helps in the formation of glucose-6-phosphate from glucose in the lumen of endoplasmic reticulum (ER) $[9,10]$. Herein, the enzyme is a part of the multicomponent system, including several integral membrane proteins, G6Pase catalytic subunit (G6PC), a regulatory $\mathrm{Ca}^{2+}$ binding protein, and glucose6-phosphatase translocase (G6PT) [11]. G6Pase activity is restricted to the various gluconeogenic tissues like liver [12], kidney [13], small intestine [14], and $\beta$-cells of the endocrine pancreas [9].

G6Pase enzyme is encoded by G6PC1, G6PC2, and G6PC3 genes which are responsible for metabolic disorders. G6PC1 is expressed in the liver, kidney, and small intestine, whereas G6PC2 is expressed in the pancreas and G6PC3 is expressed ubiquitously in the human body $[15,16]$. G6PC1 and G6PC3 are located on the 17q21 chromosome and $\mathrm{G6PC} 2$ is on the $2 \mathrm{q} 31$ chromosome. The cytosolic 


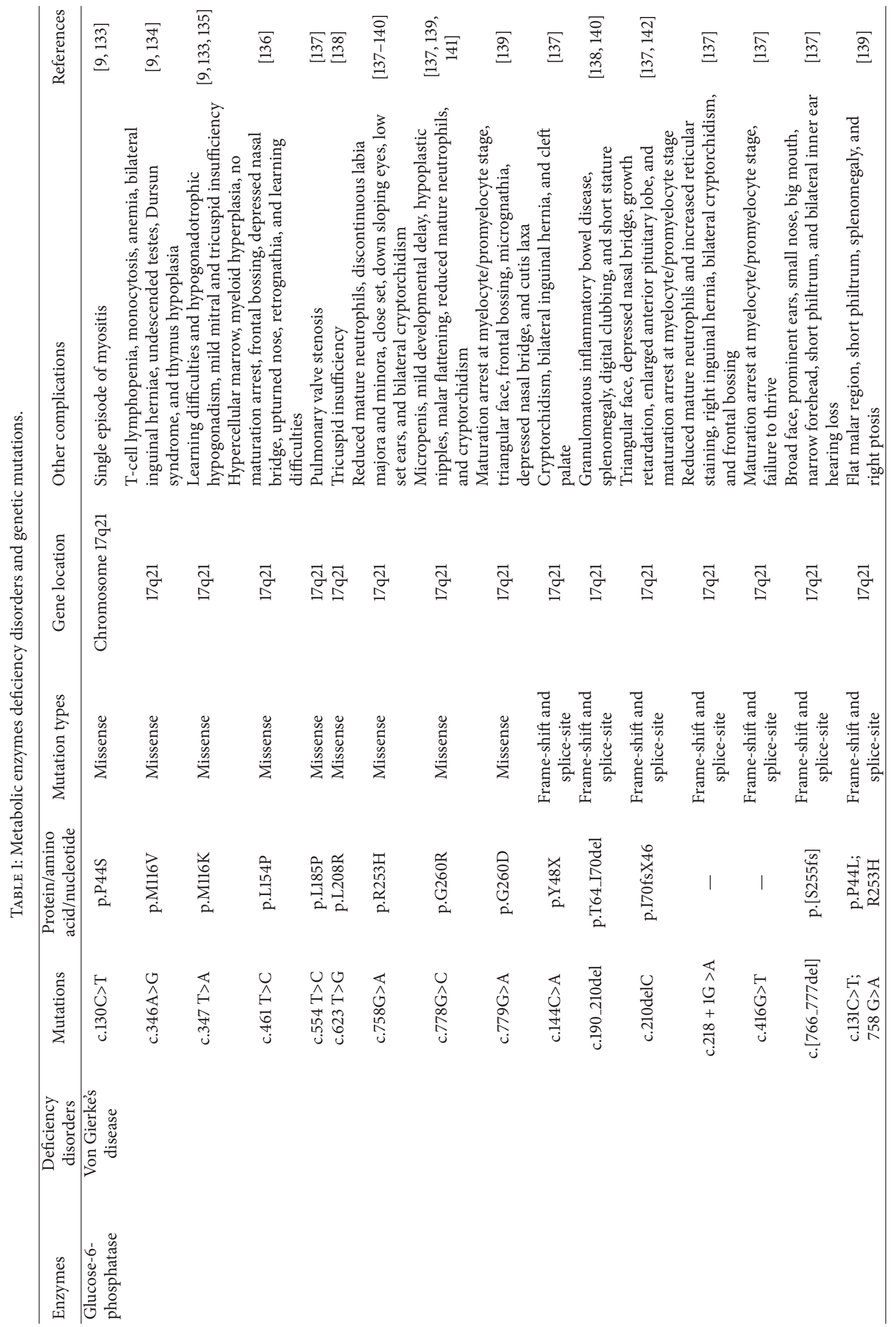




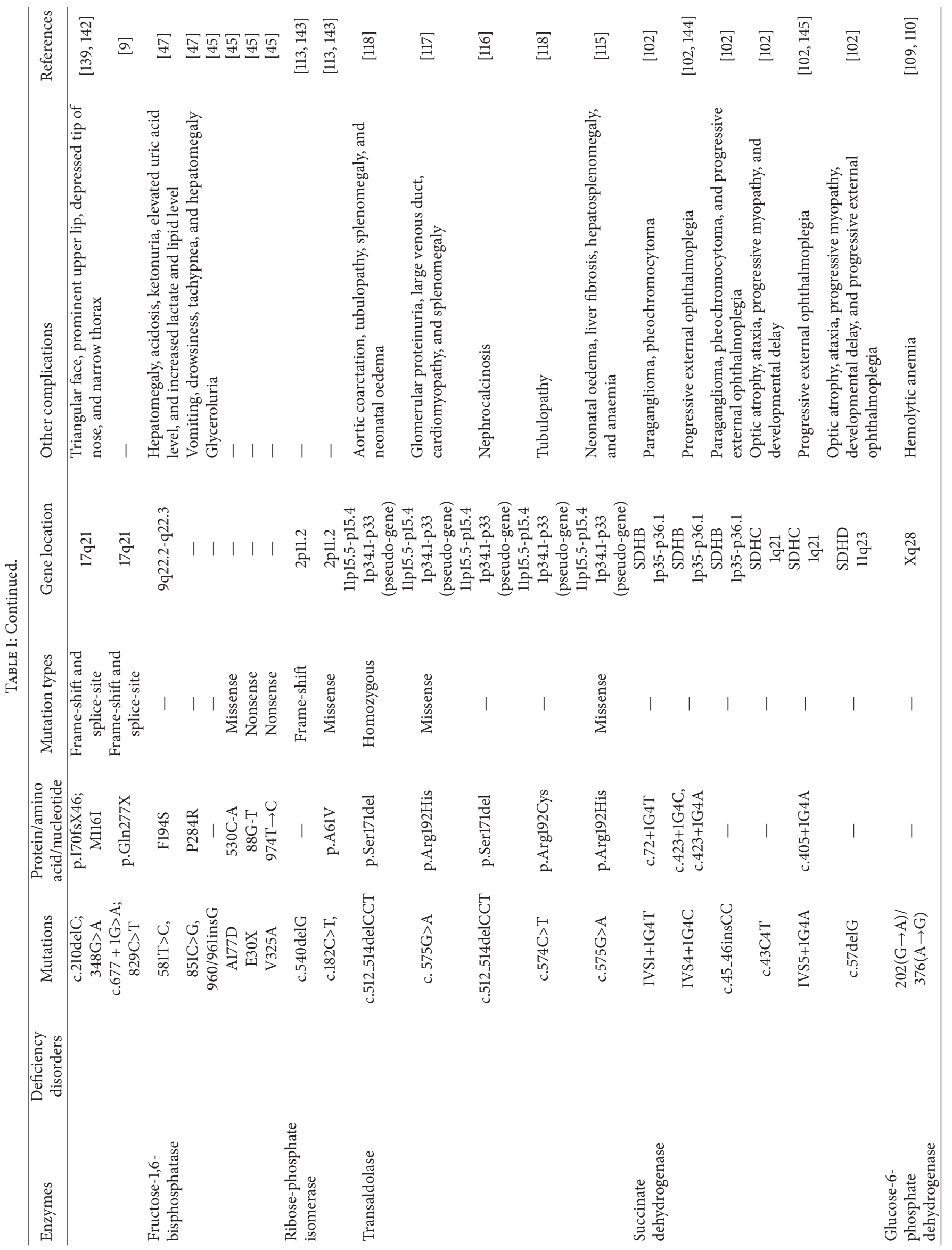




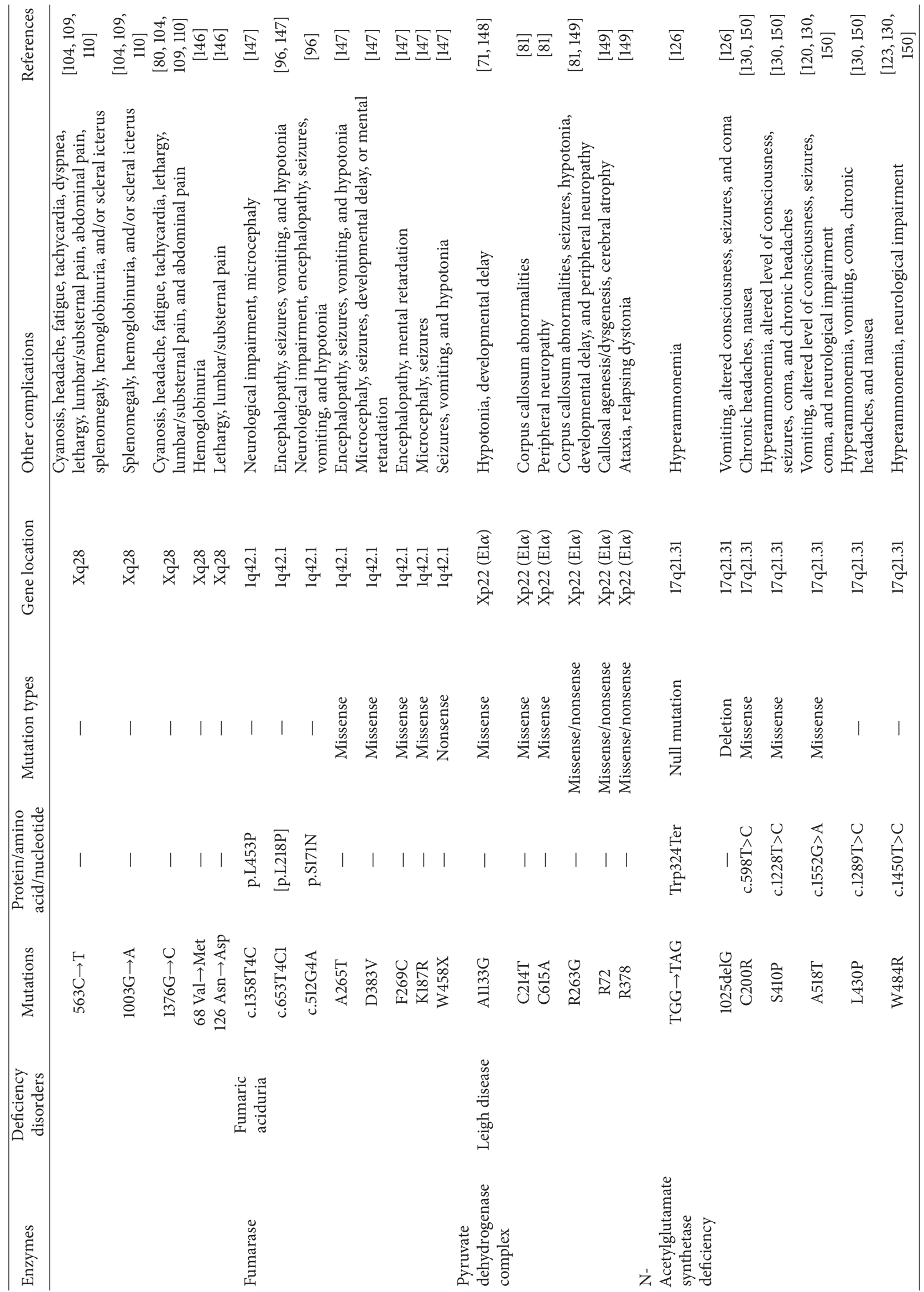


glucose-6-phosphate is transported to ER through SLC37A4 encoded gene $[17,18]$. Deficiency of G6Pase activity in liver, kidney, and intestinal mucosa with excessive accumulation of glycogen in these organs leads to glycogen storage disease (GSD) type 1 (Von Gierke's disease). The latter is considered as acute metabolic disorder preferably characterized by hypoglycemia. There are two main types of glycogen storage diseases: the first is due to a defect in G6PC, called GSD type $1 \mathrm{a}$, and the second one is due to the defect in G6PT, called GSD type $1 b[19,20]$.

GSD-1a patients are clinically diagnosed with prompt induced hypoglycemia and hyperlactacidemia in the neonatal period. Protruded abdomen due to pronounced hepatomegaly is the first symptom developed around 3 months of age. Moreover, the other biological hallmarks are hyperlipidemia, hyperuricaemia, round doll-like face, developmental delay, and late onset of puberty [20-22]. The clinical signs are chronic acidosis and hypertriglyceridemia which led to the development of osteopenia and enlarged kidneys. Long term complications may be the hepatocellular adenomas, renal complications, hyperuricaemia, and severe hypertriglyceridemia which may cause risk of pancreatitis and pulmonary hypertension [23]. In GSD-1b patients along with these symptoms, patients are also diagnosed with neutropenia, which is responsible for development of Crohn's disease $[21,24]$. In the recent studies, the antibacterial flagellin antibodies (anti-CBirl) detection in GSD-1b patients is another indication of Crohn's disease and this antibody level increased during disease state. In GSD-1b patients, splenomegaly is more common along with hepatomegaly, which is rarely found in GSD-1a patients [20, 25].

Previously, liver biopsy was the main diagnosis for the detection of G6Pase disorder. Recent advances in molecular biology involve DNA based diagnostic tests and genes cloning and G6Pase mutation database helps in diagnosis. Hitherto, more than 80 separate mutated genes are identified for G6Pase gene family, which are directly or indirectly responsible for G6Pase activity. These include missense (E110Q, D38V, P178S, W236R, R295C, and L345R), nonsense (Q347X and R170X), insertion/deletion (822delC and 813insG), and codon deletion (DF327) mutations, which are capable of reducing the G6Pase activity [19].

Naturally occurring dog and transgenic mice models are used for the study of GSD-1a whereas transgenic mice models are for GSD-1b [10, 26]. The transgenic mouse model shows all the symptoms of human GSD-1a, that is, hypoglycemia, hepatomegaly, nephromegaly, growth retardation, hyperlipidemia, mild lactic acidemia, and hyperuricemia $[10$, 26]. Crossbreeding of Beagle and Maltese (with Met121Ile mutation) showed mutation of G6PC gene with symptoms of GSD-1a [26, 27]. These animal models would serve as a useful tool for the understanding of the pathophysiological conditions and therapeutic approaches of GSD-1a deficiency [26]. Gene therapy related to adenoviral and adeno-associated virus vectors is another important therapeutic approach for G6Pase- $\alpha[28,29]$. Moreover, measurement of granulocyte colony-stimulating factor (GCSF) is an important parameter for GSD-1b diagnosis, as G-CSF may increase the number and improve the function of circulating neutrophils, and G-CSF may improve the symptoms of Crohn-like inflammatory bowel disease in individuals with GSD-1b [30, 31].

Corn starch and other carbohydrates are the primary treatment for G6Pase deficiency [32]. It is also necessary to normalize other physiological parameters during disease state of G6Pase deficiency. Allopurinol and angiotensinconverting enzyme (ACE) inhibitors are used as supplementary drug to lower the uric acid and microalbuminuria [20]. Adjunct therapy during G6Pase deficiency includes lipid lowering drugs and potassium citrate [26, 33, 34]. Liver transplantation in the patient with GSD-1a can be performed if dietary therapy becomes unresponsive to hepatocellular adenoma and tumors. Bone marrow transplantation can be undertaken for the patients with GSD-1b related myeloid deficiencies [26, 34-39].

\subsection{Fructose-1,6-bisphosphatase (FBPase) Deficiency. FBPase} is an unique enzyme in the gluconeogenetic pathway, regulated via alteration of the active (R) and inactive (T) conformational isomeric states [11, 40], which catalyzes the magnesium dependent reversible production of fructose1,6-bisphosphate from fructose-6-phosphate and inorganic phosphate [41]. The molecular weight of human FBPase is $36.7 \mathrm{KDa}$ and consists of four identical subunits of one substrate and one allosteric site. FBPase activity is regulated by fructose-2,6-bisphosphate (binds to substrate site) and adenosine monophosphate (binds to allosteric site). This enzyme is encoded by the FBP1 gene in liver and kidney at 9 q22.2 and q22.3 chromosomal site [42].

FBPase deficiency is a metabolic recessive disorder in the liver that is characterized by the life-threatening episodes of hyperventilation, hypoglycemia, apnoea, lactic acidosis, and ketosis [43, 44]. Kikawa, for the first time, identified the mutations of FBPase in ten patients of eight unrelated families, suggesting that FBP1 gene mutation is responsible for FBPase deficiency. To date, several different mutations have been published on individuals with FBPase deficiency. Among them, 960/961insG, G164S, A177D, and E30X were reported in Japanese unrelated families. Recently, two new FBP1 gene mutations, F194S and P284R, were identified in a Japanese female patient with FBPase deficiency. p.G260R, c.778G $>$ A, and p.Y216X are the newly identified mutations in Swedish patients [43, 45]. Generally, the mutations are widespread throughout the FBP1 gene, and each mutation was found in one case or family, with an exception: an insertion of guanine at position 960 that has been found in several patients with different ethnic backgrounds [46]. FBP1 gene was downregulated in Ras-mediated transformation and in gastric carcinogenesis and NF-kappa-B is involved in initiation of FBP1 gene downregulation (Warburg effect) [45-49].

The diagnosis of FBPase enzyme deficiency was determined through spectrophotometric and load tests (radiochemical) [50, 51] in liver, kidney [52], and jejunum [32]. Calcitriol stimulated FBP1 gene expression is similar to expression of vitamin $\mathrm{D}$ receptor [53]. The measurement of FBPase deficiency is observed in leucocytes [54, 55]. Later, similar activity is determined in monocytes where stimulation with calcitriol resulted in four- to sixfold enhancement of activity. Further immunoblotting technique revealed 
the presence of enzymes in monocytes but not in lymphocytes [56]. Moreover, both clinical symptoms and mutation analysis are the common methods for FBPase activity. In addition, activity assessment of liver tissue is generally used for a reliable diagnosis [49].

Glucose (10-12 mg/kg/minute, newborns) and bicarbonate $(200 \mathrm{mmol} / 24 \mathrm{~h})$ are given to control hypoglycemia and acidosis. Starch and gastric drip are frequently given during treatment but not sucrose, sorbitol, fructose, fat (20-25\%), and protein (10\%) [57].

Enhancement of FBPase activity during type 2 diabetes is the primary role as this enzyme promotes gluconeogenesis [58]. However, antidiabetics do not reduce gluconeogenesis, and therefore inhibition of FBPase activity is required separately [58-60]. The uses of selective FBPase inhibitors (adenosine monophosphate) and structure guided design strategy are the important parameters for FBPase activity. In light of the same, quite a few FBPase inhibitors are in their different stages of ongoing clinical trials (CS-917 and MB07803) [58].

\subsection{Phosphoenolpyruvate Carboxykinase (PEPCK) Deficiency.} PEPCK, an essential marker for gluconeogenesis, catalyzes the conversion of phosphoenolpyruvate to oxaloacetate. There are different isoforms of PEPCK, that is, PEPCK1 (cytosolic) and PEPCK2 (mitochondrial) [61]. PEPCK1 is localized on chromosome 20q13.31 and encodes a 622amino acid polypeptide with $91 \%$ sequence similarity to that of the rat, whereas PEPCK2 is localized on chromosome $14 q 11.2$ and encodes a 640 -amino acid polypeptide with $78 \%$ sequence identity to that of the human PEPCK1 [61, 62]. PEPCK1 is regulated by the mitochondrial GTP-dependent pathways, including hormones, substrate supply, and purine nucleotides.

Although this enzyme helps in gluconeogenesis, it has an important role in glyceroneogenesis where it helps in the synthesis of glyceride-glycerol from glucose or glycerol in adipose tissue and liver $[63,64]$. It plays another role in citric acid cycle and helps in the entry of carbon skeletons to amino acids [65]. Recently, it has been reported that the role of this enzyme in mammary gland epithelial cells (HC11 cells) is derived from COMMA-D epithelial cells and isolated from the mammary gland of pregnant $\mathrm{BALB} / \mathrm{c}$ mice $[66,67]$. Apart from this, PEPCK2 is known for its ability to fix carbon dioxide by converting pyruvate into oxaloacetic acid (Wood-Werkman pathway) [68]. Moreover, PEPCK2 is principally involved in gluconeogenesis, providing the cytosolic NADH through its conversion to pyruvate from lactic acid. This enzyme deficiency is an autosomal recessive disorder whose phenotype is not expressed clearly. Lactic acidosis and hypoglycemia are the primary symptoms for PEPCK deficiency. Reye syndrome develops due to inhibition of gluconeogenesis which, in turn, is due to PEPCK enzyme deficiency [69].

The specific symptoms of PEPCK deficiency are associated with lactic acidosis, hypoglycaemia, hepatomegaly, glucagon insensitivity, failure to thrive, Fanconi syndrome, developmental delay, hypotonia, and massive fat deposition in liver and kidneys [70].
Treatment of PEPCK deficiency includes the maintenance therapy similar to FBPase deficiency to treat acute attacks (glucose and bicarbonate infusions). There is no specific treatment other than maintaining normoglycaemia and correcting metabolic disorders.

2.4. Pyruvate Dehydrogenase Complex (PDHC) Deficiency. $\mathrm{PDHC}$ is critically involved in the conversion of pyruvate to acetyl-coenzyme A. The complex is composed of three different enzymes which are pyruvate decarboxylase (E1), dihydrolipoyl transacetylase (E2), and dihydrolipoyl dehydrogenase (E3). This complex requires five coenzymes for the reaction, three prosthetic groups (thiamine pyrophosphate, FAD, and lipoic acid), and two other carriers (coenzyme $A$ and NAD) [71]. PDHC deficiency is considered one of the most common genetic as well as neurodegenerative disorders generally associated with abnormal mitochondrial metabolism. It is an extremely heterogeneous condition, also one of the X-linked diseases in which heterozygous female exhibits severe symptoms [72-75].

Around 200 cases of PDHC deficiency were reported previously where mutation at $\mathrm{E} 1 \alpha$ subunit of $\mathrm{Xp} 22$ chromosome has occurred. 80 different mutated genes from El $\alpha$ subunit had been identified which are responsible for deficiency [7678]. Few cases of deficiency were not clearly understood and it is assumed that this happened due to alteration of recessive genes (1:50000 cases in males) [79].

Clinical spectrum of PDHC deficiency is broad and is divided into neurological as well as metabolic manifestations. Neurological presentation includes hypotonia, spasticity, dysplasia of the dentate nuclei, pachygyria, mental retardation, and Leigh syndrome. The metabolic manifestation of this enzyme deficiency occurs at neonatal period due to lactic acidosis. Maple syrup urine disease (MSUD) and energy metabolism disorder occurred during PDHC deficiency due to increased levels of plasma pyruvate, lactate, and $\alpha$-ketoglutarate [80]. Sometimes, neonatal lactic acidosis along with respiratory disturbances was observed during this enzyme deficiency state [81]. Mutations in pyruvate dehydrogenase phosphatase gene have also been recently identified [79, 82].

Diagnosis is based upon the laboratory measurements of lactate and pyruvate in blood and cerebrospinal fluid (CSF). High blood lactate and pyruvate levels in blood and cerebrospinal fluid with or without lactic acidemia suggest the deficiency of PDHC. Furthermore, lactate-to-pyruvate ratio is diagnostically useful to differentiate PDHC deficiency from other forms of congenital lactic acidosis at higher lactate levels $(>5 \mathrm{mmol} / \mathrm{L})$. A low $\mathrm{L}: \mathrm{P}$ ratio is observed in inherited disorders of PDHC deficiency. As in the case of PDHC deficiency, the mutation arises from the germ cells of one of the parents and the majority of children die before they reach their adulthood; the prenatal diagnosis is extremely useful for diagnosing patients before they are born so that treatment can be initiated immediately after birth. The identification of mutated gene deficit and genetic analysis in pregnancies is one of the most reliable methods for prenatal diagnosis [82]. In prenatal diagnosis, cultured chorionic villus cells are the most reliable to measure enzymatic activity. In male foetus, 
it is easy to diagnose with confidence, but in female foetus, it becomes difficult due to extreme skewing of X-chromosome inactivation.

Treatment includes the ketogenic diet, an important rational strategy for $\mathrm{PDHC}$ deficiency, but it does not improve the neurological symptoms and structural damage in the brain. Thiamine at variable doses and dichloroacetate at $50 \mathrm{mg} / \mathrm{kg}$ were found to be effective in some patients for potential treatment of PDHC deficiency and around 40 cases have been treated with the same. The combination of DCA and thiamine can be given in chronic cases but thiamine with ketogenic diet should be tried in each and every patient $[72,82]$.

\subsection{Succinate Dehydrogenase (SDH) Deficiency. SDH (succi-} nate ubiquinone oxidoreductase) is composed of heterotetrameric protein with SDHA and SDHB subunits, which bulge into mitochondria and coupled with inner membrane by SDHC and SDHD subunits (ubiquinone attachment site). All these subunits together are called complex II, which helps in Krebs cycle [83]. The four subunits of SDH are encoded by four nuclear genes located on chromosomes 1p35-p36.1, 5p15, 1q21, and 11q23 [84, 85]. Leigh's syndrome, also known as subacute necrotising encephalomyelopathy (SNEM), is a neurodegenerative disorder and is associated with $\mathrm{SDH}$ deficiency due to mutation [86].

PGL4 syndrome (pheochromocytoma/paraganglioma syndrome type 4 ) is characterized by gastrointestinal stromal tumors and renal tumors and are usually classified as carcinoma. PGL4 syndrome is caused by SDHB deficiency which is due to the missense mutation. Moreover, hereditary paraganglioma and pheochromocytoma is the main disease state for SDH deficiency which occurs due to mutation of SDHB, SDHC or SDHD subunits $[87,88]$. The similar diseases also occur due to mutation of SDHA and SDH subunits assembly factor $2[89,90]$. Various disorders such as Leigh syndrome, progressive myopathy, ophthalmoplegia, optic atrophy, and ataxia are the main clinical manifestations during SDH deficiency [91, 92]. Treatment of this enzyme deficiency is symptomatic.

2.6. Fumarase or Fumarate Hydratase (FH) Deficiency. FH catalyzes the conversion of fumarate to malate which is responsible for autosomal recessive disorder in the Krebs cycle. There are two types of fumarase isoenzymes, present in cytosol and mitochondria. Mitochondrial fumarate hydratase is responsible for catalytic reversible conversion of fumarate to malate during citric acid cycle whereas cytosolic fumarase is involved in fumarate metabolism during urea cycle [93].

The mutant alleles of the $\mathrm{FH}$ gene are located on human chromosome 1 at position 1q42.1. [94-96]. However, genetic analysis revealed that mutation occurs at $435 \mathrm{insK}$ chromosome for several patients (GenBank U59309) whereas the other mutations seemed to be private mutations [97-100]. The FH gene is similar to tumor suppressor gene, related to renal cell cancer and hereditary leiomyomatosis [101, 102].

Fumaric aciduria occurs during FH deficiency, characterized by neurological impairment, encephalopathy, and seizures, which causes death in childhood [86]. Neuropathological changes include choroid plexus cysts, polymicrogyria, and hypomyelination which occurs at white matter of brain in old ages [97, 103]. FH enzyme concentration is measured in blood leukocytes, liver, and skin fibroblasts during deficiency state (via coupling reaction with malate dehydrogenase) [86, 101]. Unfortunately, to date, there is no specific treatment yet to be employed effectively.

2.7. Glucose-6-phosphate Dehydrogenase (G6PD) Deficiency. G6PD works in pentose phosphate (PPP) pathway and helps in the reduction of nicotinamide adenine dinucleotide phosphate (NADPH). G6PD serves as antioxidant enzyme where it donates one electron to oxidised glutathione (GSSG) which converts into reduced glutathione (GSH) [80, 104]. The deficiency syndrome also relates to X-linked hereditary disorder [104-107]. G6PD deficiency occurs everywhere due to de novo mutations [108]. There are 160 different mutated genes, which is responsible for G6PD deficiency. The gene involved in the disease is located on Xq28, containing 13 exons, and encoded by a protein with 515 amino acids. A G6PD gene mutation distribution rate differs from one geographic area to another $[104,109]$. G6PD A-202 $(\mathrm{G} \rightarrow \mathrm{A}) / 376(\mathrm{~A} \rightarrow \mathrm{G})$ is the most widespread mutation in the African continent. A G6PD gene mutation called "Mediterranean" has also frequently been distributed from Mediterranean and Middle Eastern countries to the Indian subcontinent. It is the most common mutation among patients from the northern provinces of Iran. Apart from these, Chatham and Cosenza, the two other common G6PD gene mutations, have the highest frequency rates in those areas [110-112].

The patients with G6PD deficiency suffer from cyanosis, headache, fatigue, tachycardia, dyspnoea, lethargy, lumbar/ substernal pain, abdominal pain, splenomegaly, hemoglobinuria, and/or scleral icterus. Moreover, the broken down products of hemoglobin may accumulate in the blood, causing jaundice, and are excreted in urine, causing dark brown discoloration [80].

2.8. Ribose-5-phosphate Isomerase (RPI) Deficiency. RPI is an enzyme of PPP pathway, which catalyzes the conversion between ribulose-5-phosphate (Ru5P) and ribose-5phosphate (R5P). With a much lower number of diagnosed patients, RPI deficiency is currently the rarest disease in the world $[113,114]$. During RPI deficiency, the human is attacked by epilepsy, followed by weakening of speech, vision, hand coordination, and walking [114].

It contains 2p11.2 gene having 9 exons and 311 amino acids. Deficiency of this enzyme is found to be caused by a combination of two mutations. The first is a deletion (c.540delG) and the second is a missense mutation (c.182C $>$ T) of 2 p11.2 gene [113].

The disease is clinically specified by leukoencephalopathy and mild peripheral polyneuropathy. Other neurological parameters like prominent cerebellar ataxia, nystagmus, bilateral optic atrophy, and spasticity were also observed during this enzyme deficiency [113].

The levels of D-xylulose, ribose, ribitol, and arabitol are increased in urine during deficiency state and therefore the 
diagnosis of this enzyme deficiency is performed by the concentration of sugars and polyols in the urine sample. Diagnosis may also be undertaken through the enzymatic assay in fibroblasts and sequence analysis of R5P gene. There is no specific treatment available for such deficiency [80].

2.9. Transaldolase (TALDO) Deficiency. TALDO is a nonoxidative enzyme of pentose phosphate pathway, which is involved in making a correlation between PPP and glycolysis pathways. Transaldolase (TALDO) deficiency is a newly recognized metabolic disease, which has been reported so far in 2 patients presenting with liver failure and cirrhosis. Deficiency of this enzyme shows elevation of polyols and seven-carbon sugars (erythritol, arabitol, and ribitol) in the body [113].

TALDO gene is composed of 11p15.5-p15.4 chromosome with another pseudogene at 1p34.1-p33 chromosome. TALDO deficiency is caused by mutation in TALDO 1 gene in the form of c.575C>T (p.Arg192Cys), c.574G $>A$ (p.Arg192His), and c.512-514delCCT $[115,116]$.

The common clinical symptoms include bleeding problems, hepatosplenomegaly, enlarged clitoris, liver cirrhosis, thrombocytopenia, elevated bile acid with normal bilirubin, and mildly prolonged prothrombin time during deficiency of TALDO. In addition, the patient may suffer from respiratory failure, progressive myocardial hypertrophy, bradycardia, severe lactic acidosis, and liver failure [117-119].

The deficiency of TALDO enzyme is diagnosed by elevated concentrations of ribitol, arabitol, and erythritol in urine sample. The elevated concentrations of these markers are more prominent in neonatal stage and older patients $[118,119]$. There is no specific treatment available for TALDO deficiency. Liver transplantation is an alternative approach for liver cirrhosis which occurred during this enzyme deficiency $[117,118]$.

\subsection{N-Acetylglutamate Synthase (NAGS) Deficiency. NAGS} is present in the small intestine and liver which acts as an important enzyme to regulate ureagenesis [120-122]. In urea cycle, $\mathrm{N}$-acetylglutamate (NAG) is required as the allosteric activator of carbamylphosphate synthetase, a rate limiting enzyme of the urea cycle. NAGS catalyzes the conversion of glutamate to NAG by combining with Acetyl-CoA. This is why the deficiency in NAGS leads to hyperammonemia [123].

NAGS deficiency is the rarest autosomal, recessive, inherited metabolic disorder, which is characterized by hyperammonemia [120, 121, 124, 125]. NAGS deficiency is clinically characterized by seizures, poor feeding, hyperammonemia, coma, and chronic headaches $[123,124]$. The biochemical estimation of all intermediates except elevated plasma ammonia and glutamine shows normal results. Moreover, urinary orotic acid level is not elevated during deficiency of this enzyme [126, 127]. However, diagnosis can be achieved by hepatic enzymatic studies [127] but in some cases it is not reliable $[128,129]$. Therefore, accurate diagnosis is performed by cloning of the NAGS gene [127]. The gene is located on chromosome 17q21.31 consisting of 7 exons and 6 introns. Mutations in the NAGS gene include 15 missense, 1 nonsense, 4 frame-shift, and 2 splice-site mutations [130].
NAGS deficiency is the only inherited urea cycle disorder that can be specifically and effectively treated by a drug $\mathrm{N}$ carbamylglutamate (NCG) which appears to be beneficial for the treatment of hyperammonemic conditions and increases the rate of ureagenesis [131].

During deficiency of this enzyme, arginine supplement, sodium phenylacetate, sodium benzoate, and sodium phenylbutyrate are generally given to scavenge the excess ammonia [132].

\section{Conclusion}

Contribution of mutational approach to detection of real cause associated with metabolic enzymes deficiency has allowed the design of "tailor-made" therapeutic strategies to alleviate most of the metabolic diseases. The original cause of most metabolic enzyme disorders is an IEM, particularly gene mutations. However, there is a significant level of tolerance in the system. For example, a mutation in one enzyme does not mean that the individual will suffer from a disease because a number of different enzymes may compete to modify the same metabolic step. Unless a critical enzyme is disabled, disease will not arise. To recognize a distinct and welldefined reason of metabolic disorder, therefore, even now remains a challenge. While the field of metabolism related research continues to grow and expand, we have gained much knowledge and insight into the impact of gene mutation as a causal factor of metabolic disorders and potential new techniques to be employed in the future. These innovative insights will be an important review from which future research may continue to grow and expand.

\section{Conflict of Interests}

The authors declare no conflict of interests.

\section{Acknowledgment}

Dr. Sudipta Saha wishes to express his thanks to the University Grants Commission (UGC), New Delhi, India, for providing UGC-MRP grant (Project no. 42-680/2013(SR)).

\section{References}

[1] A. E. Vasdekis and G. Stephanopoulos, "Review of methods to probe single cell metabolism and bioenergetics," Metabolic Engineering, vol. 27, pp. 115-135, 2015.

[2] S. Chanprasert and F. Scaglia, "Adult liver disorders caused by inborn errors of metabolism: review and update," Molecular Genetics and Metabolism, vol. 114, no. 1, pp. 1-10, 2015.

[3] S. Sharma, P. Kumar, R. Agarwal, M. Kabra, A. Deorari, and V. Paul, "Approach to inborn errors of metabolism presenting in the neonate," Indian Journal of Pediatrics, vol. 75, no. 3, pp. 271276, 2010.

[4] B. A. Barshop, "Metabolic disease," Genetics, vol. 3, pp. 37-46, 2003.

[5] National Institutes of Health, "NINDS, handout on lipid storage diseases fact sheet," NIH Publication 05-2628, 2005.

[6] Metabolic Backgrounder: The Ross Metabolic Formula System for Meeting Special Nutrition Needs, Ross Products Division, Columbus, Ohio, USA, 2007. 
[7] B. Wilcken, "An introduction to nutritional treatment in Inborn errors of metabolism-different disorders, different approaches," The Southeast Asian Journal of Tropical medicine and Public Health, vol. 34, pp. 198-201, 2003.

[8] K. M. Hendricks and C. Duggan, Manual of Pediatric Nutrition, BC Decker, 4th edition, 2005.

[9] S. Banka, R. Wynn, H. Byers, P. D. Arkwright, and W. G. Newman, "G6PC3 mutations cause non-syndromic severe congenital neutropenia," Molecular Genetics and Metabolism, vol. 108, no. 2, pp. 138-141, 2013.

[10] K.-J. Lei, H. Chen, C.-J. Pan et al., "Glucose-6-phosphatase dependent substrate transport in the glycogen storage disease type-la mouse," Nature Genetics, vol. 13, no. 2, pp. 203-209, 1996.

[11] E. V. Schaftingen, "Fructose 2,6-bisphosphate," Advances in Enzymology and Related areas of Molecular Biology, vol. 59, pp. 315-395, 1987.

[12] J. Ashmore, A. B. Hastings, F. B. Nesbett, and A. E. Renold, "Studies on carbohydrate metabolism in rat liver slices. VI. Hormonal factors influencing glucose-6-phosphatise," The Journal of Biological Chemistry, vol. 218, pp. 77-88, 1956.

[13] G. Wirthensohn and W. G. Guder, "Renal substrate metabolism," Physiological Reviews, vol. 66, no. 2, pp. 469-497, 1986.

[14] F. Rajas, N. Bruni, S. Montano, C. Zitoun, and G. Mithieux, "The glucose- 6 phosphatase gene is expressed in human and rat small intestine: regulation of expression in fasted and diabetic rats," Gastroenterology, vol. 117, no. 1, pp. 132-139, 1999.

[15] D. Azzout-Marniche, C. Gaudichon, C. Blouet et al., "Liver glyconeogenesis: a pathway to cope with postprandial amino acid excess in high-protein fed rats?" The American Journal of Physiology-Regulatory Integrative and Comparative Physiology, vol. 292, no. 4, pp. R1400-R1407, 2007.

[16] A. Benedetti, R. Fulceri, M. Ferro, and M. Comporti, "On a possible role for glucose-6-phosphatase in the regulation of liver cell cytosolic calcium concentration," Trends in Biochemical Sciences, vol. 11, no. 7, pp. 284-285, 1986.

[17] K. Boztug, P. S. Rosenberg, M. Dorda et al., "Extended spectrum of human glucose-6-phosphatase catalytic subunit 3 deficiency: novel genotypes and phenotypic variability in severe congenital neutropenia," Journal of Pediatrics, vol. 160, no. 4, pp. 679.e2683.e2, 2012.

[18] J. C. Hutton and R. M. O’Brien, "Glucose-6-phosphatase catalytic subunit gene family," The Journal of Biological Chemistry, vol. 284, no. 43, pp. 29241-29245, 2009.

[19] J. Yang Chou and B. C. Mansfield, "Molecular genetics of type 1 glycogen storage diseases," Trends in Endocrinology and Metabolism, vol. 10, no. 3, pp. 104-113, 1999.

[20] R. Froissart, M. Piraud, A. M. Boudjemline et al., "Glucose-6phosphatase deficiency," Orphanet Journal of Rare Diseases, vol. 6, article 27, 2011.

[21] P. Marcolongo, R. Fulceri, A. Gamberucci, I. Czegle, G. Banhegyi, and A. Benedetti, "Multiple roles of glucose-6-phosphatases in pathophysiology: state of the art and future trends," Biochimica et Biophysica Acta (BBA)-General Subjects, vol. 1830, no. 3, pp. 2608-2618, 2013.

[22] Y. T. Chen, “Glycogen storage diseases," in The Metabolic Bases of Inherited Disease, pp. 1521-1551, McGraw-Hill, New York, NY, USA, 8th edition, 2000.

[23] Y. T. Chen and J. L. Van Hove, "Renal involvement in type I glycogen storage disease," Advances in nephrology from the Necker Hospital, vol. 24, pp. 357-365, 1995.
[24] S. Efendic, S. Karlander, and M. Vranic, "Mild type II diabetes markedly increases glucose cycling in the postabsorptive state and during glucose infusion irrespective of obesity," The Journal of Clinical Investigation, vol. 81, no. 6, pp. 1953-1961, 1988.

[25] Y. T. Chen and A. Burchell, The Metabolic Basis of Inherited Disease, McGraw-Hill, New York, NY, USA, 7th edition, 1995.

[26] J. Y. Chou, H. S. Jun, and B. C. Mansfield, "Glycogen storage disease type I and G6Pase- $\beta$ deficiency: etiology and therapy," Nature Reviews Endocrinology, vol. 6, no. 12, pp. 676-688, 2010.

[27] P. S. Kishnani, E. Faulkner, S. VanCamp et al., "Canine model and genomic structural organization of glycogen storage disease type Ia (GSD Ia)," Veterinary Pathology, vol. 38, no. 1, pp. 83-91, 2001.

[28] A. Zingone, H. Hiraiwa, C.-J. Pan et al., "Correction of glycogen storage disease type la in a mouse model by gene therapy," The Journal of Biological Chemistry, vol. 275, no. 2, pp. 828-832, 2000.

[29] D. D. Koeberl, B. Sun, A. Bird, Y. T. Chen, K. Oka, and L. Chan, "Efficacy of helper-dependent adenovirus vector-mediated gene therapy in murine glycogen storage disease type Ia," Molecular Therapy, vol. 15, no. 7, pp. 1253-1258, 2007.

[30] G. Visser, J.-P. Rake, J. Fernandes et al., "Neutropenia, neutrophil dysfunction, and inflammatory bowel disease in glycogen storage disease type Ib: results of the European study on glycogen storage disease type I," Journal of Pediatrics, vol. 137, no. 2, pp. 187-191, 2000.

[31] B. K. Dieckgraefe, J. R. Korzenik, A. Husain, and L. Dieruf, "Association of glycogen storage disease $1 \mathrm{~b}$ and Crohn disease: results of a North American survey," European Journal of Pediatrics, vol. 161, no. 1, pp. S88-S92, 2002.

[32] H. L. Greene, F. B. Stifel, and R. H. Herman, "Ketotic hypoglycemia' due to hepatic fructose-1,6-diphosphatase deficiency: treatment with folic acid," The American Journal of Diseases of Children, vol. 124, no. 3, pp. 415-418, 1972.

[33] D. D. Koeberl, P. S. Kishnani, D. Bali, and Y.-T. Chen, "Emerging therapies for glycogen storage disease type I," Trends in Endocrinology and Metabolism, vol. 20, no. 5, pp. 252-258, 2009.

[34] D. H. J. Martens, J. P. Rake, G. Navis, V. Fidler, C. M. L. Van Dael, and G. P. A. Smit, "Renal function in glycogen storage disease type I, natural course, and renopreservative effects of ACE inhibition," Clinical Journal of the American Society of Nephrology, vol. 4, no. 11, pp. 1741-1746, 2009.

[35] D. Matern, T. E. Starzl, W. Arnaout et al., "Liver transplantation for glycogen storage disease types I, III, and IV," European Journal of Pediatrics, vol. 158, supplement 2, pp. S43-S48, 1999.

[36] L. Fatvre, D. Houssin, J. Valayer, J. Brouard, M. Hadchouel, and O. Bernard, "Long-term outcome of liver transplantation in patients with glycogen storage disease type Ia," Journal of Inherited Metabolic Disease, vol. 22, no. 6, pp. 723-732, 1999.

[37] M. K. Davis and D. A. Weinstein, "Liver transplantation in children with glycogen storage disease: controversies and evaluation of the risk/benefit of this procedure," Pediatric Transplantation, vol. 12, no. 2, pp. 137-145, 2008.

[38] S. K. Reddy, S. L. Austin, M. Spencer-Manzon et al., "Liver transplantation for glycogen storage disease type Ia," Journal of Hepatology, vol. 51, no. 3, pp. 483-490, 2009.

[39] P. Labrune, "Glycogen storage disease type I: indications for liver and/or kidney transplantation," European Journal of Pediatrics, Supplement, vol. 161, no. 1, pp. S53-S55, 2002. 
[40] S. Heng, K. M. Harris, and E. R. Kantrowitz, "Designing inhibitors against fructose 1,6-bisphosphatase: exploring natural products for novel inhibitor scaffolds," European Journal of Medicinal Chemistry, vol. 45, no. 4, pp. 1478-1484, 2010.

[41] P. D. V. Poelje, S. C. Potter, and M. D. Erion, "Fructose-1, 6bisphosphatase inhibitors for reducing excessive endogenous glucose production in type 2 diabetes," in Diabetes-Perspectives in Drug Therapy, vol. 203 of Handbook of Experimental Pharmacology, pp. 279-301, Springer, Berlin, Germany, 2011.

[42] M. R. El-Maghrabi, A. J. Lange, W. Jiang et al., "Human fructose1,6-bisphosphatase gene (FBP1): exon-intron organization, localization to chromosome bands 9q22.2-q22.3, and mutation screening in subjects with fructose-1,6-bisphosphatase deficiency," Genomics, vol. 27, no. 3, pp. 520-525, 1995.

[43] S. Moon, J.-H. Kim, J.-H. Han et al., "Novel compound heterozygous mutations in the fructose-1,6-bisphosphatase gene cause hypoglycemia and lactic acidosis," Metabolism: Clinical and Experimental, vol. 60, no. 1, pp. 107-113, 2011.

[44] A. A. M. Morris, S. Deshpande, M. P. Ward-Platt et al., "Impaired ketogenesis in fructose-1,6-bisphosphatase deficiency: a pitfall in the investigation of hypoglycaemia," Journal of Inherited Metabolic Disease, vol. 18, no. 1, pp. 28-32, 1995.

[45] Y. Kikawa, M. Inuzuka, B. Y. Jin et al., "Identification of genetic mutations in Japanese patients with fructose-1,6-bisphosphatase deficiency," The American Journal of Human Genetics, vol. 61, no. 4, pp. 852-861, 1997.

[46] M. Faiyaz-Ul-Haque, M. Al-Owain, F. Al-Dayel et al., "Novel FBP1 gene mutations in Arab patients with fructose-1,6bisphosphatase deficiency," European Journal of Pediatrics, vol. 168, no. 12, pp. 1467-1471, 2009.

[47] T. Matsuura, Y. Chinen, R. Arashiro et al., “Two newly identified genomic mutations in a Japanese female patient with fructose1,6-bisphosphatase (FBPase) deficiency," Molecular Genetics and Metabolism, vol. 76, no. 3, pp. 207-210, 2002.

[48] B. Herzog, U. Wendel, A. A. M. Morris, and K. Eschrich, "Novel mutations in patients with fructose-1,6-bisphosphatase deficiency," Journal of Inherited Metabolic Disease, vol. 22, no. 2, pp. 132-138, 1999.

[49] P. Prahl, E. Christensen, L. Hansen, and H. B. Mortensen, "Fructose 1,6-bisphosphatase deficiency as a cause of recessive serious hypoglycaemia," Ugeskrift for Lager, vol. 168, no. 46, pp. 4014-4015, 2006.

[50] L. Baker and A. I. Winegrad, "Fasting hypoglycaemia and metabolic acidosis associated with deficiency of hepatic fructose-1, 6-diphosphatase activity," The Lancet, vol. 296, no. 7662, pp. 13-16, 1970.

[51] A. J. M. Janssen and F. J. M. Trijbels, "A new radiochemical assay for fructose-1,6-diphosphatase in human leucocytes," Clinica Chimica Acta, vol. 119, no. 1-2, pp. 143-148, 1982.

[52] S. B. Melancon, A. K. Khachadurian, H. L. Nadler, and B. I. Brown, "Metabolic and biochemical studies in fructose 1, 6diphosphatase deficiency," The Journal of Pediatrics, vol. 82, no. 4, pp. 650-657, 1973.

[53] D. H. Solomon, M. C. Raynal, G. A. Tejwani, and Y. E. Cayre, "Activation of the fructose 1,6-bisphosphatase gene by 1,25dihydroxyvitamin D3 during monocytic differentiation," Proceedings of the National Academy of Sciences of the United States of America, vol. 85, no. 18, pp. 6904-6908, 1988.

[54] D. Alexander, M. Assaf, A. Khudr, I. Haddad, and A. Barakat, "Fructose-1,6-diphosphatase deficiency: diagnosis using leukocytes and detection of heterozygotes with radiochemical and spectrophotometric methods," Journal of Inherited Metabolic Disease, vol. 8, no. 4, pp. 174-177, 1985.

[55] A. B. Burlina, M. Poletto, Y. S. Shin, and F. Zacchello, "Clinical and biochemical observations on three cases of fructose1, 6-diphosphatase deficiency," Journal of Inherited Metabolic Disease, vol. 13, no. 3, pp. 263-266, 1990.

[56] Y. Kikawa, T. Takano, A. Nakai et al., "Monocytes, not lymphocytes, show increased fructose-1,6-diphosphatase activity during culture," Journal of Inherited Metabolic Disease, vol. 16, no. 5, pp. 913-914, 1993.

[57] "Disorders of fructose metabolism," in Metabolic and Molecular Bases of Inherited Disease, B. Steinmann, R. Gitzelmann, G. Van den Berghe, C. R. Scriver, A. L. Beaudet, and W. S. D. V. Sly, Eds., pp. 1489-1520, McGraw-Hill, New York, NY, USA, 2001.

[58] P. D. van Poelje, Q. Dang, and M. D. Erion, "Fructose-1,6bisphosphatase as a therapeutic target for type 2 diabetes," Drug Discovery Today: Therapeutic Strategies, vol. 4, no. 2, pp. 103-109, 2007.

[59] M. D. Erion, P. D. Van Poelje, Q. Dang et al., "MB06322 (CS-917): a potent and selective inhibitor of fructose 1,6bisphosphatase for controlling gluconeogenesis in type 2 diabetes," Proceedings of the National Academy of Sciences of the United States of America, vol. 102, no. 22, pp. 7970-7975, 2005.

[60] P. D. van Poelje, S. C. Potter, V. C. Chandramouli, B. R. Landau, Q. Dang, and M. D. Erion, "Inhibition of fructose 1,6bisphosphatase reduces excessive endogenous glucose production and attenuates hyperglycemia in Zucker diabetic fatty rats," Diabetes, vol. 55, no. 6, pp. 1747-1754, 2006.

[61] R. Stark and R. G. Kibbey, "The mitochondrial isoform of phosphoenolpyruvate carboxykinase (PEPCK-M) and glucose homeostasis: has it been overlooked?" Biochimica et Biophysica Acta (BBA)-General Subjects, vol. 1840, no. 4, pp. 1313-1330, 2014.

[62] S. Modaressi, K. Brechtel, B. Christ, and K. Jungermann, "Human mitochondrial phosphoenolpyruvate carboxykinase 2 gene. Structure, chromosomal localization and tissue-specific expression," Biochemical Journal, vol. 333, no. 2, pp. 359-366, 1998.

[63] L. Reshef, R. W. Hanson, and F. J. Ballard, "A possible physiological role for glyceroneogenesis in rat adipose tissue," The Journal of Biological Chemistry, vol. 245, no. 22, pp. 5979-5984, 1970.

[64] S. C. Kalhan, S. Mahajan, E. Burkett, L. Reshef, and R. W. Hanson, "Glyceroneogenesis and the source of glycerol for hepatic triacylglycerol synthesis in humans," The Journal of Biological Chemistry, vol. 276, no. 16, pp. 12928-12931, 2001.

[65] P. Hakimi, M. T. Johnson, J. Yang et al., "Phosphoenolpyruvate carboxykinase and the critical role of cataplerosis in the control of hepatic metabolism," Nutrition and Metabolism, vol. 2, article 33, 2005.

[66] C.-W. Hsieh, C. Huang, I. Bederman et al., "Function of phosphoenolpyruvate carboxykinase in mammary gland epithelial cells," Journal of Lipid Research, vol. 52, no. 7, pp. 1352-1362, 2011.

[67] R. K. Ball, R. R. Friis, C. A. Schoenenberger, W. Doppler, and B. Groner, "Prolactin regulation of beta-casein gene expression and of a cytosolic 120-kd protein in a cloned mouse mammary epithelial cell line," The EMBO Journal, vol. 7, no. 7, pp. 20892095, 1988.

[68] R. W. Hanson, “Thematic minireview series: a perspective on the biology of phosphoenolpyruvate carboxykinase 55 years after its discovery," The Journal of Biological Chemistry, vol. 284, no. 40, pp. 27021-27023, 2009. 
[69] M. Adeva-Andany, M. López-Ojén, R. Funcasta-Calderón et al., "Comprehensive review on lactate metabolism in human health," Mitochondrion, vol. 17, pp. 76-100, 2014.

[70] S. Chandran, F. Yap, and K. Hussain, "Genetic disorders leading to hypoglycaemia," Journal of Genetic Syndromes \& Gene Therapy, vol. 4, article 192, 2013.

[71] B. H. Robinson, N. MacKay, K. Chun, and M. Ling, "Disorders of pyruvate carboxylase and the pyruvate dehydrogenase complex," Journal of Inherited Metabolic Disease, vol. 19, no. 4, pp. 452-462, 1996.

[72] R. E. Frye and P. J. Benke, "Pyruvate Dehydrogenase Complex Deficiency," 2014, http://emedicine.medscape.com/article/ 948360-overview.

[73] B. H. Robinson, K. Chun, N. Mackay, G. Otulakowski, R. Petrova-Benedict, and H. Willard, "Isolated and combined deficiencies of the alpha-keto acid dehydrogenase complexes," Annals of the New York Academy of Sciences, vol. 573, pp. 337346, 1989.

[74] G. K. Brown, R. M. Brown, R. D. Scholem, D. M. Kirby, and H.H. M. Dahl, "The clinical and biochemical spectrum of human pyruvate dehydrogenase complex deficiency," Annals of the New York Academy of Sciences, vol. 573, pp. 360-368, 1989.

[75] M. S. Patel and T. E. Roche, "Molecular biology and biochemistry of pyruvate dehydrogenase complexes," The FASEB Journal, vol. 4, no. 14, pp. 3224-3233, 1990.

[76] B. H. Robinson, N. MacKay, K. Chun, and M. Ling, "Disorders of pyruvate carboxylase and the pyruvate dehydrogenase complex," Journal of Inherited Metabolic Disease, vol. 19, no. 4, pp. 452-462, 1996.

[77] D. S. Kerr, I. D. Wexler, A. Tripatara, and M. S. Patel, "Defects of the human pyruvate dehydrogenase complex," in Alpha Keto Acid Dehydrogenase Complexes, M. S. Patel, T. Roche, and R. A. Harris, Eds., pp. 249-270, Birkhäuser, Basel, Switzerland, 1996.

[78] L. J. Otero, R. M. Brown, and G. K. Brown, "Arginine 302 mutations in the pyruvate dehydrogenase El $\alpha$ subunit gene: identification of further patients and in vitro demonstration of pathogenicity," Human Mutation, vol. 12, no. 2, pp. 114-121, 1998.

[79] J. Steller, J. J. Gargus, L. H. Gibbs, A. N. Hasso, and V. E. Kimonis, "Mild phenotype in a male with pyruvate dehydrogenase complex deficiency associated with novel hemizygous in-frame duplication of the el $\alpha$ subunit gene (PDHA1)," Neuropediatrics, vol. 45, no. 1, pp. 56-60, 2014.

[80] J. Fernandes, J. M. Saudubray, G. V. D. Berghe, and J. H. Walter, Inborn Metabolic Diseases: Diagnosis and Treatment, Springer Medizin, Heidelberg, Germany, 2006.

[81] K. P. Patel, T. W. O’Brien, S. H. Subramony, J. Shuster, and P. W. Stacpoole, "The spectrum of pyruvate dehydrogenase complex deficiency: clinical, biochemical and genetic features in 371 patients," Molecular Genetics and Metabolism, vol. 105, no. 1, pp. 34-43, 2012.

[82] G. K. Brown, L. J. Otero, M. LeGris, and R. M. Brown, "Pyruvate dehydrogenase deficiency," Journal of Medical Genetics, vol. 31, no. 11, pp. 875-879, 1994.

[83] C. Bardella, P. J. Pollard, and I. Tomlinson, "SDH mutations in cancer," Biochimica et Biophysica Acta-Bioenergetics, vol. 1807, no. 11, pp. 1432-1443, 2011.

[84] P. Heutink, A. G. L. van der Mey, L. A. Sandkuijl et al., "A gene subject to genomic imprinting and responsible for hereditary paragangliomas maps to chromosome 11q23-qter," Human Molecular Genetics, vol. 1, no. 1, pp. 7-10, 1992.
[85] B. E. Baysal, J. E. Farr, W. S. Rubinstein et al., "Fine mapping of an imprinted gene for familial nonchromaffin paragangliomas, on chromosome 11q23," American Journal of Human Genetics, vol. 60, no. 1, pp. 121-132, 1997.

[86] T. Bourgeron, D. Chretien, J. Poggi-Bach et al., "Mutation of the fumarase gene in two siblings with progressive encephalopathy and fumarase deficiency," The Journal of Clinical Investigation, vol. 93, no. 6, pp. 2514-2518, 1994.

[87] B. E. Baysal, J. E. Willett-Brozick, E. C. Lawrence et al., "Prevalence of SDHB, SDHC, and SDHD germline mutations in clinic patients with head and neck paragangliomas," Journal of Medical Genetics, vol. 39, no. 3, pp. 178-183, 2002.

[88] P. J. Pollard, N. C. Wortham, and I. P. M. Tomlinson, "The TCA cycle and tumorigenesis: the examples of fumarate hydratase and succinate dehydrogenase," Annals of Medicine, vol. 35, no. 8, pp. 632-639, 2003.

[89] N. Burnichon, J.-J. Brière, R. Libé et al., "SDHA is a tumor suppressor gene causing paraganglioma," Human Molecular Genetics, vol. 19, no. 15, pp. 3011-3020, 2010.

[90] H.-X. Hao, O. Khalimonchuk, M. Schraders et al., "SDH5, a gene required for flavination of succinate dehydrogenase, is mutated in paraganglioma," Science, vol. 325, no. 5944, pp. 11391142, 2009.

[91] S. Rahman, R. B. Blok, H.-H. M. Dahl et al., "Leigh syndrome: clinical features and biochemical and DNA abnormalities," Annals of Neurology, vol. 39, no. 3, pp. 343-351, 1996.

[92] M. H. Rivner, M. Shamsnia, T. R. Swift et al., "Kearns-Sayre syndrome and complex II deficiency," Neurology, vol. 39, no. 5, pp. 693-696, 1989.

[93] M. Deschauer, Z. Gizatullina, A. Schulze et al., "Molecular and biochemical investigations in fumarase deficiency," Molecular Genetics and Metabolism, vol. 88, no. 2, pp. 146-152, 2006.

[94] T. Suzuki, M. Sato, T. Yoshida, and S. Tuboi, "Rat liver mitochondrial and cytosolic fumarases with identical amino acid sequences are encoded from a single gene," The Journal of Biological Chemistry, vol. 264, no. 5, pp. 2581-2586, 1989.

[95] C. Ottolenghi, L. Hubert, Y. Allanore et al., "Clinical and biochemical heterogeneity associated with fumarase deficiency," Human Mutation, vol. 32, no. 9, pp. 1046-1052, 2011.

[96] E. M. Coughlin, E. Christensen, P. L. Kunz et al., "Molecular analysis and prenatal diagnosis of human fumarase deficiency," Molecular Genetics and Metabolism, vol. 63, no. 4, pp. 254-262, 1998.

[97] J. Loeffen, R. Smeets, T. Voit, G. Hoffmann, and J. Smeitink, "Fumarase deficiency presenting with periventricular cysts," Journal of Inherited Metabolic Disease, vol. 28, no. 5, pp. 799800, 2005.

[98] N. A. Alam, A. J. Rowan, N. C. Wortham et al., "Genetic and functional analyses of FH mutations in multiple cutaneous and uterine leiomyomatosis, hereditary leiomyomatosis and renal cancer, and fumarate hydratase deficiency," Human Molecular Genetics, vol. 12, no. 11, pp. 1241-1252, 2003.

[99] A. M. Remes, S. A. Filppula, H. Rantala et al., "A novel mutation of the fumarase gene in a family with autosomal recessive fumarase deficiency," Journal of Molecular Medicine, vol. 82, no. 8, pp. 550-554, 2004.

[100] J. Zeman, J. Krijt, L. Stratilová et al., "Abnormalities in succinylpurines in fumarase deficiency: possible role in pathogenesis of CNS impairment," Journal of Inherited Metabolic Disease, vol. 23, no. 4, pp. 371-374, 2000. 
[101] I. P. M. Tomlinson, N. A. Alam, A. J. Rowan et al., "Germline mutations in FH predispose to dominantly inherited uterine fibroids, skin leiomyomata and papillary renal cell cancer the multiple leiomyoma consortium," Nature Genetics, vol. 30, no. 4, pp. 406-410, 2002.

[102] P. Rustin and A. Rötig, "Inborn errors of complex II-unusual human mitochondrial diseases," Biochimica et Biophysica Acta (BBA)-Bioenergetics, vol. 1553, no. 1-2, pp. 117-122, 2002.

[103] J. R. Toro, M. L. Nickerson, M.-H. Wei et al., "Mutations in the fumarate hydratase gene cause hereditary leiomyomatosis and renal cell cancer in families in North America," The American Journal of Human Genetics, vol. 73, no. 1, pp. 95-106, 2003.

[104] E. Beutler, “G6PD deficiency," Blood, vol. 84, no. 11, pp. 36133636, 1994.

[105] P. J. Mason, J. M. Bautista, and F. Gilsanz, "G6PD deficiency: the genotype-phenotype association," Blood Reviews, vol. 21, no. 5, pp. 267-283, 2007.

[106] L. Luzzatto, T. J. Vulliamy, and A. Mehta, "Glucose 6-phosphate dehydrogenase deficiency," in The Metabolic and Molecular Bases of Inherited Disease, pp. 4517-4553, McGraw Hill, 2001.

[107] J. E. Frank, "Diagnosis and management of G6PD deficiency," American Family Physician, vol. 72, no. 7, pp. 1277-1282, 2005.

[108] C. J. Sutherland, N. Tanomsing, D. Nolder et al., "Two non recombining sympatric forms of the human malaria parasite Plasmodium ovale occur globally," The Journal of Infectious Diseases, vol. 201, no. 10, pp. 1544-1550, 2010.

[109] M. R. N. Daloii, Z. Hajebrahimi, and L. Najafi, "Molecular identification of the most prevalent mutation of glucose-6phosphate dehydrogenase gene in deficient patients in Gilan province," Journal of Sciences, Islamic Republic of Iran, vol. 14, pp. 327-331, 2003.

[110] A. Dallol, H. Banni, M. A. Gari et al., "Five novel glucose6-phosphate dehydrogenase deficiency haplotypes correlating with disease severity," Journal of Translational Medicine, vol. 10, article 199, 2012.

[111] N. Laouini, A. Bibi, H. Ammar et al., "Glucose-6-phosphate dehydrogenase deficiency in Tunisia: molecular data and phenotype-genotype association," Molecular Biology Reports, vol. 40, no. 2, pp. 851-856, 2013.

[112] M. Cappellini and G. Fiorelli, "Glucose-6-phosphate dehydrogenase deficiency," The Lancet, vol. 371, no. 9606, pp. 64-74, 2008.

[113] M. M. C. Wamelink, E. A. Struys, and C. Jakobs, "The biochemistry, metabolism and inherited defects of the pentose phosphate pathway: a review," Journal of Inherited Metabolic Disease, vol. 31, no. 6, pp. 703-717, 2008.

[114] J. H. J. Huck, N. M. Verhoeven, E. A. Struys, G. S. Salomons, C. Jakobs, and M. S. Van Der Knaap, "Ribose-5-phosphate isomerase deficiency: new inborn error in the pentose phosphate pathway associated with a slowly progressive leukoencephalopathy," American Journal of Human Genetics, vol. 74, no. 4, pp. 745-751, 2004.

[115] M. M. Wamelink, E. A. Struys, G. S. Salomons, D. Fowler, C. Jakobs, and P. T. Clayton, "Transaldolase deficiency in a two-year-old boy with cirrhosis," Molecular Genetics and Metabolism, vol. 94, no. 2, pp. 255-258, 2008.

[116] S. Thorell, P. Gergely Jr., K. Banki, A. Perl, and G. Schneider, "The three-dimensional structure of human transaldolase," FEBS Letters, vol. 475, no. 3, pp. 205-208, 2000.

[117] C. W. Fung, S. Siu, C. Mak et al., "A rare cause of hepatosplenomegaly-transaldolase deficiency," Journal of Inherited Metabolic Disease, vol. 30, supplement 1, article 62, 2007.
[118] V. Valayannopoulos, N. M. Verhoeven, K. Mention et al., "Transaldolase deficiency: a new cause of hydrops fetalis and neonatal multi-organ disease," Journal of Pediatrics, vol. 149, no. 5, pp. 713-717, 2006.

[119] N. M. Verhoeven, M. Wallot, J. H. J. Huck et al., "A newborn with severe liver failure, cardiomyopathy and transaldolase deficiency," Journal of Inherited Metabolic Disease, vol. 28, no. 2, pp. 169-179, 2005.

[120] E. Schmidt, J.-M. Nuoffer, J. Häberle et al., "Identification of novel mutations of the human $N$-acetylglutamate synthase gene and their functional investigation by expression studies," Biochimica et Biophysica Acta (BBA)_Molecular Basis of Disease, vol. 1740, no. 1, pp. 54-59, 2005.

[121] C. Bachmann, S. Krähenbühl, J. P. Colombo, G. Schubiger, K. H. Jaggi, and O. Tönz, "N-acetylglutamate synthetase deficiency: a disorder of ammonia detoxication," The New England Journal of Medicine, vol. 304, no. 9, pp. 543-345, 1981.

[122] A. J. Meijer, C. Lof, I. C. Ramos, and A. J. Verhoeven, "Control of ureogenesis," European Journal of Biochemistry, vol. 148, no. 1, pp. 189-196, 1985.

[123] N. A. Mew and L. Caldovic, "N-acetylglutamate synthase deficiency: an insight into the genetics, epidemiology, pathophysiology, and treatment," The Application of Clinical Genetics, vol. 4, pp. 127-135, 2011.

[124] L. Caldovic, H. Morizono, M. G. Panglao et al., "Late onset $\mathrm{N}$-acetylglutamate synthase deficiency caused by hypomorphic alleles," Human Mutation, vol. 25, no. 3, pp. 293-298, 2005.

[125] C. Bachmann, M. Brandis, E. Weissenbarth-Riedel, R. Burghard, and J. P. Colombo, "Nacetylglutamate synthetase deficiency, a second patient," Journal of Inherited Metabolic Disease, vol. 11, pp. 191-193, 1988.

[126] L. Caldovic, H. Morizono, M. G. Panglao, S. F. Cheng, S. Packman, and M. Tuchman, "Null mutations in the N-acetylglutamate synthase gene associated with acute neonatal disease and hyperammonemia," Human Genetics, vol. 112, no. 4, pp. 364-368, 2003.

[127] L. Caldovic, N. Ah Mew, D. Shi, H. Morizono, M. Yudkoff, and M. Tuchman, "N-acetylglutamate synthase: structure, function and defects," Molecular Genetics and Metabolism, vol. 100, supplement, pp. S13-S19, 2010.

[128] M. Heckmann, B. Wermuth, J. Häberle, H. G. Koch, L. Gortner, and J. G. Kreuder, "Misleading diagnosis of partial Nacetylglutamate synthase deficiency based on enzyme measurement corrected by mutation analysis," Acta Paediatrica, vol. 94, no. 1, pp. 121-124, 2005.

[129] W.-L. Hwu, Y.-H. Chien, N. L. Tang, L.-K. Law, C.-Y. Lin, and N.-C. Lee, "Deficiency of the carnitine transporter (OCTN2) with partial N-acetylglutamate synthase (NAGS) deficiency," Journal of Inherited Metabolic Disease, vol. 30, no. 5, article 816, 2007.

[130] J. Häberle, E. Schmidt, S. Pauli et al., "Mutation analysis in patients with $\mathrm{N}$-acetylglutamate synthase deficiency," Human Mutation, vol. 21, no. 6, pp. 593-597, 2003.

[131] L. Caldovic, N. A. Mew, D. Shi, H. Morizono, M. Yudkoff, and M. Tuchman, "N-acetylglutamate synthase: structure, function and defects," Molecular Genetics and Metabolism, vol. 100, pp. S13-S19, 2010.

[132] G. M. Enns, S. A. Berry, G. T. Berry, W. J. Rhead, S. W. Brusilow, and A. Hamosh, "Survival after treatment with phenylacetate and benzoate for urea-cycle disorders," The New England Journal of Medicine, vol. 356, no. 22, pp. 2282-2292, 2007. 
[133] S. Banka, R. Wynn, and W. G. Newman, "Variability of bone marrow morphology in G6PC3 mutations: is there a genotypephenotype correlation or age-dependent relationship?" American Journal of Hematology, vol. 86, no. 2, pp. 235-237, 2011.

[134] A. Dursun, R. K. Ozgul, A. Soydas et al., "Familial pulmonary arterial hypertension, leucopenia, and atrial septal defect: a probable new familial syndrome with multisystem involvement," Clinical Dysmorphology, vol. 18, no. 1, pp. 19-23, 2009.

[135] M. Germeshausen, C. Zeidler, M. Stuhrmann, M. Lanciotti, M. Ballmaier, and K. Welte, "Digenic mutations in severe congenital neutropenia," Haematologica, vol. 95, no. 7, pp. 12071210, 2010.

[136] C. Aytekin, M. Germeshausen, N. Tuygun, F. Dogu, and A. Ikinciogullari, "A novel G6PC3 gene mutation in a patient with severe congenital neutropenia," Journal of Pediatric Hematology/Oncology, vol. 35, no. 2, pp. e81-e83, 2013.

[137] K. Boztug, G. Appaswamy, A. Ashikov et al., "A syndrome with congenital neutropenia and mutations in G6PC3," The New England Journal of Medicine, vol. 360, no. 1, pp. 32-43, 2009.

[138] B. N. Smith, C. Evans, A. Ali et al., "Phenotypic heterogeneity and evidence of a founder effect associated with G6PC3 mutations in patients with severe congenital neutropenia," British Journal of Haematology, vol. 158, no. 1, pp. 146-149, 2012.

[139] K. Boztug, P. S. Rosenberg, M. Dorda et al., "Extended spectrum of human glucose-6-phosphatase catalytic subunit 3 deficiency: novel genotypes and phenotypic variability in severe congenital neutropenia," Journal of Pediatrics, vol. 160, no. 4, pp. 679-e2, 2012.

[140] B. Hayee, A. Antonopoulos, E. J. Murphy et al., "G6PC3 mutations are associated with a major defect of glycosylation: a novel mechanism for neutrophil dysfunction," Glycobiology, vol. 21, no. 7, pp. 914-924, 2011.

[141] D. H. McDermott, S. S. De Ravin, H. S. Jun et al., "Severe congenital neutropenia resulting from G6PC3 deficiency with increased neutrophil CXCR4 expression and myelokathexis," Blood, vol. 116, no. 15, pp. 2793-2802, 2010.

[142] J. Xia, A. A. Bolyard, E. Rodger et al., "Prevalence of mutations in ELANE, GFI1, HAX1, SBDS, WAS and G6PC3 in patients with severe congenital neutropenia," British Journal of Haematology, vol. 147, no. 4, pp. 535-542, 2009.

[143] M. Graille, P. Meyer, N. Leulliot et al., "Crystal structure of the S. cerevisiae D-ribose-5-phosphate isomerase: comparison with the archaeal and bacterial enzymes," Biochimie, vol. 87, no. 8, pp. 763-769, 2005.

[144] L. Amar, J. Bertherat, E. Baudin et al., "Genetic testing in pheochromocytoma or functional paraganglioma," Journal of Clinical Oncology, vol. 23, no. 34, pp. 8812-8818, 2005.

[145] F. Schiavi, C. C. Boedeker, B. Bausch et al., "Predictors and prevalence of paraganglioma syndrome associated with mutations of the SDHC gene," The Journal of the American Medical Association, vol. 294, no. 16, pp. 2057-2063, 2005.

[146] M. Town, J. M. Bautista, P. J. Mason, and L. Luzzatto, "Both mutations in G6PD A-are necessary to produce the G6PD deficient phenotype," Human Molecular Genetics, vol. 1, no. 3, pp. 171-174, 1992.

[147] S. Despoisses, L. Noel, A. Choiset et al., "Regional mapping of FH to band 1q42.1 by gene dosage studies," Cytogenetics and Cell Genetics, vol. 37, pp. 450-451, 1984.

[148] C. Barnerias, J.-M. Saudubray, G. Touati et al., "Pyruvate dehydrogenase complex deficiency: four neurological phenotypes with differing pathogenesis," Developmental Medicine and Child Neurology, vol. 52, no. 2, pp. el-e9, 2010.
[149] W. Lissens, L. De Meirleir, S. Seneca et al., "Mutations in the X-linked pyruvate dehydrogenase (E1) alpha subunit gene (PDHAl) in patients with a pyruvate dehydrogenase complex deficiency," Human Mutation, vol. 15, pp. 209-219, 2000.

[150] O. Elpeleg, A. Shaag, E. Ben-Shalom, T. Schmid, and C. Bachmann, " $N$-acetylglutamate synthase deficiency and the treatment of hyperammonemic encephalopathy," Annals of Neurology, vol. 52, no. 6, pp. 845-849, 2002. 

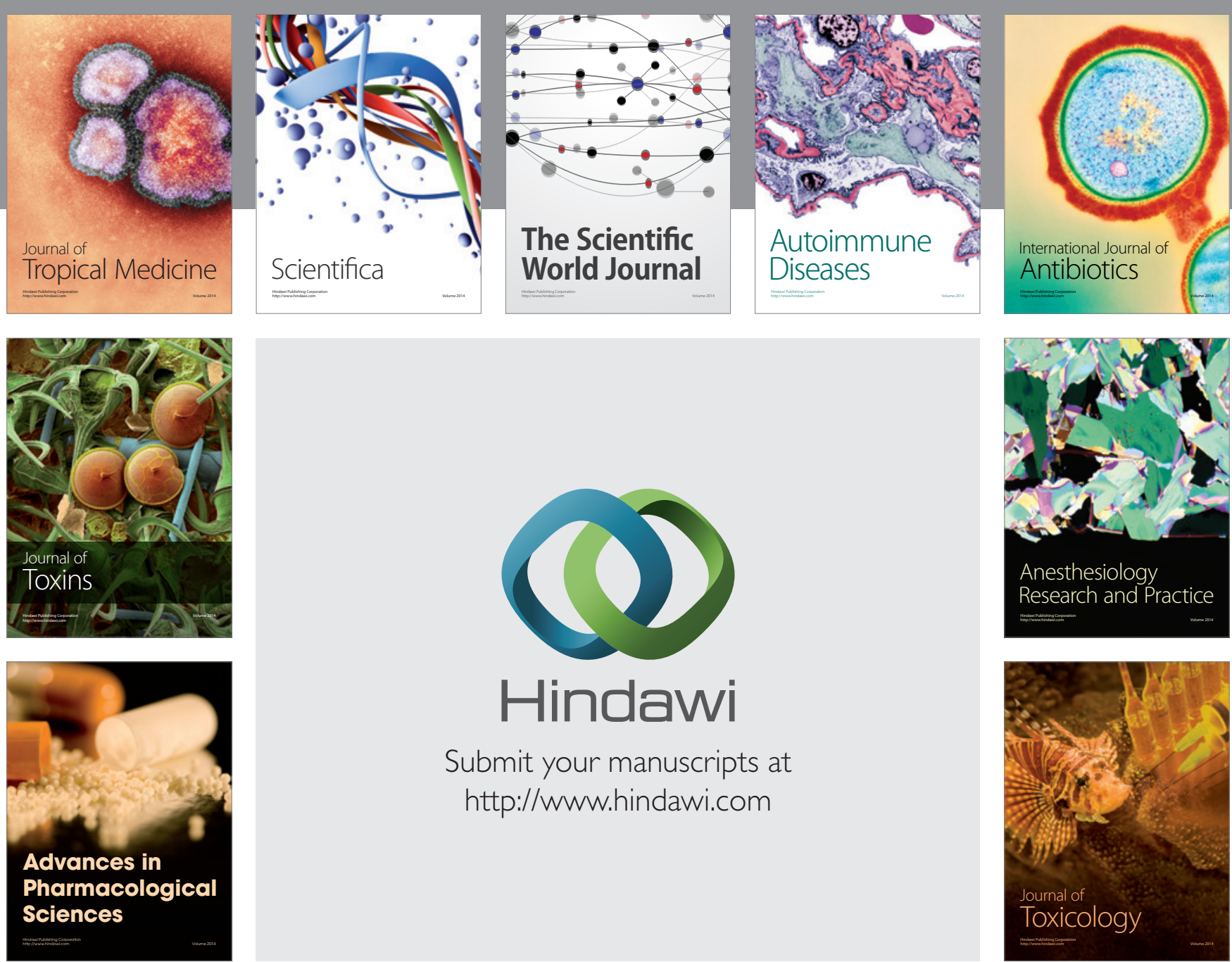

\section{Hindawi}

Submit your manuscripts at

http://www.hindawi.com
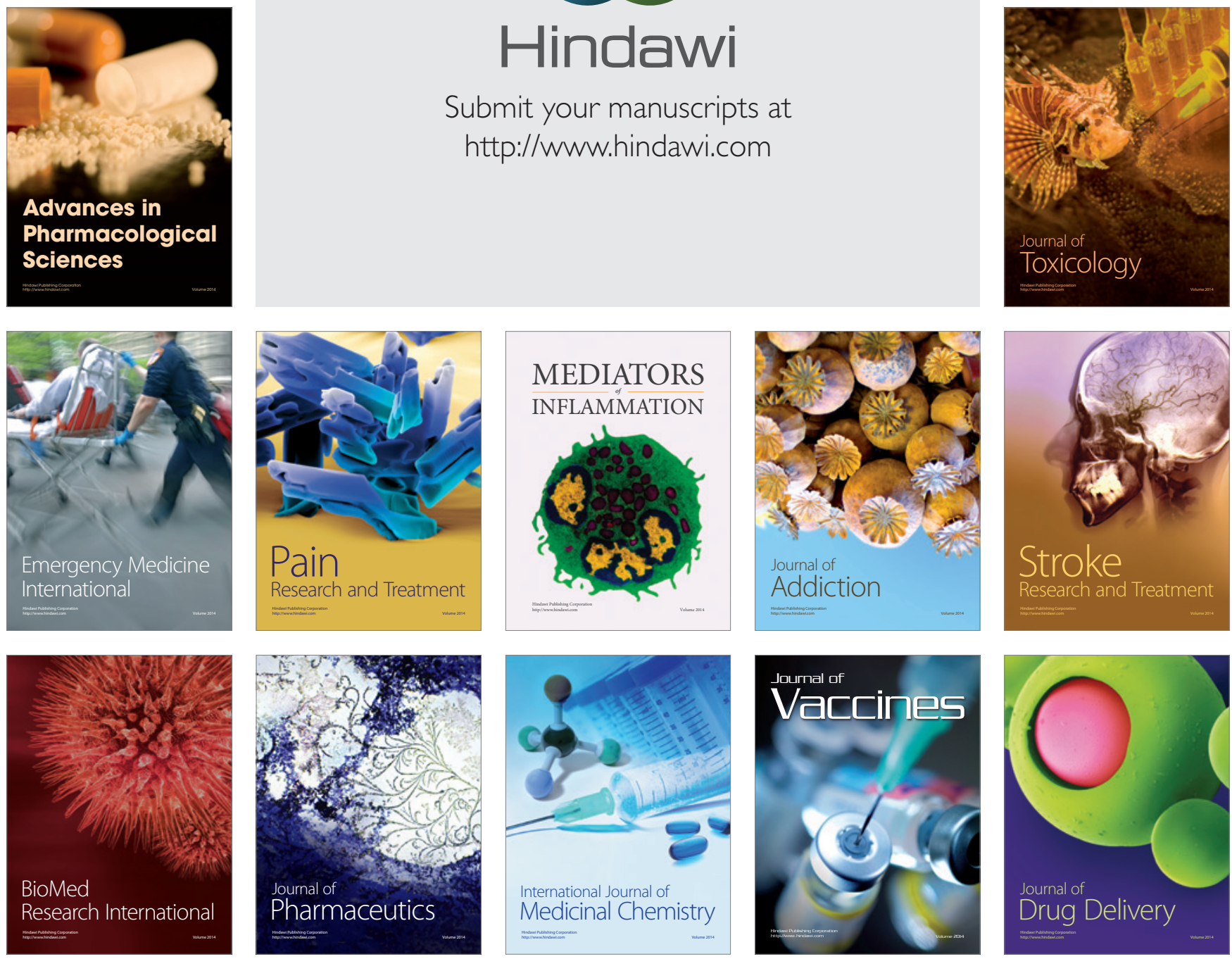